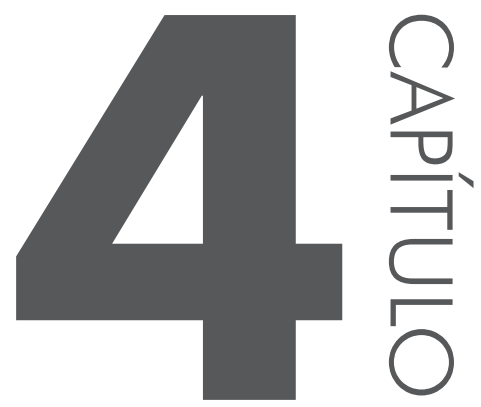

\title{
Variação discursiva: procedimentos metodológicos para delimitação do envelope de variação
}

Edair Maria Görski

Carla Regina Martins Valle

\subsection{INTRODUC̣ÃO}

Em uma visão panorâmica dos estudos no âmbito da Sociolinguística Variacionista no Brasil, ancorados na Teoria da Variação e Mudança (TVM), percebemos que desde a década de 1980 há pesquisas que se voltam à análise de fenômenos de variação considerando uma abordagem funcional, como podemos notar em trabalhos desenvolvidos no Programa de Estudos do Uso da Língua - PEUL/UFRJ (cf. SILVA; SCHERRE, 1996). A coletânea Variação e discurso, organizada por Macedo, Roncarati e Mollica (1996), reúne textos que apresentam resultados de pesquisas que investigam fenômenos linguísticos diversos à luz de um tratamento que as autoras identificam como "discursivo-funcional", envolvendo aspectos textuais, argumentativos, pragmáticos, entre outros. O título do livro, nesse caso, remete tanto a fenômenos de natureza discursiva - caso dos marcadores conversacionais -, como a contextos discursivos em que se manifesta um dado fenômeno variável em estudo - caso dos tempos e modos verbais, por 
exemplo. Em uma retrospectiva sociolinguística com as contribuições do PEUL, Paiva e Scherre (1999) ressaltam trabalhos do grupo que alargam os domínios da variação para além do nível morfossintático, incorporando nos estudos variacionistas "fatores ligados à organização do discurso, ao processamento da fala e ao processo interacional” (p. 207). Freitag (2009), ao discutir problemas teóricometodológicos para o estudo da variação em níveis gramaticais mais altos que a fonologia, utiliza o termo "variação discursiva" para designar tanto a variação no uso de marcadores discursivos, como os condicionamentos discursivos que influenciam a escolha de variantes de natureza morfossintática, por exemplo. $\mathrm{Na}$ obra Variação estilística: reflexões teórico-metodológicas e propostas de análise, organizada por Görski, Coelho e Nunes de Souza (2014), diversos capítulos contemplam condicionadores discursivos - como gêneros textuais, sequências discursivas e tópico -, e também fenômenos discursivos variáveis - como marcadores de natureza textual-interativa e conectores responsáveis pela relação coesiva de sequenciação de informações. Na apresentação do livro Para conhecer sociolinguística (COELHO et al., 2015), os autores associam a variação discursiva a fenômenos variáveis na dimensão textual/discursiva - tais como encadeadores coesivos (conectores e marcadores discursivos) -, e também a condicionadores de natureza textual/discursiva - tais como escopo semântico e temático.

Essa rápida remissão a alguns trabalhos da área aponta para o fato de que a associação dos termos variação e discursoldiscursivo(a) tem aparecido progressivamente nos estudos sociolinguísticos brasileiros nos últimos trinta anos. Não se trata, portanto, de uma novidade na área. No entanto, trata-se de uma abordagem cujo tratamento metodológico, dadas as características dos fenômenos envolvidos, requer um delineamento mais claro de suas etapas, em relação ao que costuma ser dispensado a fenômenos de níveis gramaticais mais baixos - o que já vem sendo apontado em vários trabalhos (cf. NARO; BRAGA, 2000; GÖRSKI; TAVARES; FREITAG, 2008; FREITAG, 2009; ROST SNICHELOTTO, 2009; GÖRSKI; TAVARES, 2013; TAVARES, 2003; 2013; VALLE, 2014; TAVARES; GÖRSKI, no prelo; entre outros).

Comecemos ajustando a terminologia. Variação discursiva: o que esse rótulo quer dizer? No campo da sociolinguística variacionista, o termo variação remete ao processo pelo qual duas ou mais formas linguísticas podem ocorrer com o mesmo valor representacional, ou significado referencial. ${ }^{1}$ Essas formas intercambiáveis (variantes) constituem uma variável, ou seja, um fenômeno linguístico em variação. Ocorre que o termo variável, além de designar o objeto

\footnotetext{
1 Vale registrar que Labov (2008) prevê também a possibilidade de se incluir no estudo de variação situações em que há significados alternativos para uma mesma forma.
} 
de estudo - também chamado de variável dependente em análises estatísticas - designa ainda os contextos em que se dá a variação - também chamados de variáveis independentes, fatores que condicionam a escolha dos falantes entre uma ou outra variante. Assim, o termo variação tem uma abrangência mais ampla que o termo variável.

Ainda no âmbito da sociolinguística variacionista, o termo discurso tem sido utilizado com diferentes acepções: pode se referir à organização da linguagem acima da sentença, remetendo à ideia de texto, e/ou pode remeter ao uso linguístico na interação, envolvendo também aspectos pragmáticos. Ao longo deste capítulo, a palavra discurso (e também o adjetivo derivado discursivo) será empregada indistintamente nessas duas acepções.

Entendemos, pois, por variação discursiva o processo que envolve fenômenos variáveis no nível discursivo tomados como objeto de análise, bem como condicionamentos de natureza discursiva. Para os propósitos deste capítulo, vamos nos ater ao primeiro aspecto: fenômenos variáveis no nível discursivo. Nesse sentido, o termo variável discursiva vai se referir, ao longo do texto, ao fenômeno que corresponde ao objeto de estudo do investigador. Isso posto, os objetivos deste capítulo são: (i) desenvolver uma reflexão teórico-metodológica acerca do tratamento sociolinguístico dispensado a variáveis discursivas; (ii) reforçar a discussão sobre a necessidade de haver critérios claros e articulados para delimitar o envelope de variação; e (iii) ilustrar a discussão apresentando critérios específicos para delimitação de uma variável discursiva particular.

Cumpre, por fim, esclarecer que não é nossa pretensão propor critérios generalizáveis a todas as variáveis discursivas, à moda de protocolo, já que a configuração dos fenômenos discursivos passíveis de análise variacionista é multifacetada, e cada pesquisador vai elaborar seus próprios critérios para delimitação da variável considerando as especificidades do objeto a ser investigado. Nossa intenção é enfatizar a necessidade de acionar mecanismos metodológicos objetivos e articulados para cercar fenômenos gramaticais mais altos tomados como variáveis, particularmente no sentido de decidir que itens entram e que itens não entram no envelope de variação, e definir configurações possíveis para variáveis a partir de um fenômeno discursivo.

O texto se organiza em torno dos seguintes tópicos: a) contextualização dos níveis de análise; b) análise sociolinguística de fenômenos discursivos, com enfoque primeiramente em alguns antecedentes e, na sequência, no desenho do envelope de variação, contemplando desde passos iniciais até critérios para delimitação de uma variável discursiva. 


\subsection{CONTEXTUALIZANDO OS NÍVEIS DE ANÁLISE}

Como é amplamente conhecido na área, estudos variacionistas tradicionalmente tidos como os primeiros trabalhos sistemáticos realizados na linha sociolinguística laboviana, na década de 1960, focalizavam fenômenos fonético-fonológicos, como a realização do (r) em posição pós-vocálica em Nova York (cf. LABOV, 2008). A preocupação inicial era evidenciar que os fenômenos variáveis são socialmente estratificados, e, na medida do possível, comparar resultados entre diferentes fenômenos e variedades distintas em busca do estabelecimento de padrões sociolinguísticos de variação.

Embora a maioria dos estudos variacionistas iniciais tenham se dedicado à análise de fenômenos fonético-fonológicos, alguns trabalhos já se ocupavam de variação morfológica, como contração e apagamento da cópula no inglês vernacular afro-americano (he is wild/he $\varnothing$ wild) (cf. LABOV, 2008), entre outros - casos em que o foco de atenção do pesquisador recaía também sobre os condicionadores internos da variação. No âmbito da sintaxe, um estudo de Labov em coautoria com Weiner (1983) investiga os condicionamentos do uso variável das construções passiva sem agente e ativa com sujeito pronominal genérico no inglês (The closet was broken into/Somebody broke into the closet). Nesse estudo, os fatores internos, notadamente o paralelismo estrutural, é que se mostraram significativos para o fenômeno variável, e nenhum dos fatores sociais controlados (sexo, classe social e etnia) foi selecionado.

Dessa sucinta descrição, podemos extrair as seguintes constatações, com base em trabalhos seminais de Labov: a variação está presente em diferentes níveis gramaticais; e a correlação entre variáveis linguísticas e os fatores sociais testados nem sempre mostra relevância estatística. Ademais, podemos inferir que o requisito de equivalência semântica das variantes se torna mais difícil de ser atendido à medida que o nível linguístico fica mais alto, pois formas morfológicas e sintáticas são portadoras de significado, diferentemente de formas fonológicas, que são apenas distintivas. Em níveis mais altos, aspectos de ordem semânticopragmática influenciam a ocorrência das variantes. Some-se a isso o fato de que a frequência de variáveis não fonológicas costuma ser relativamente menor na fala espontânea, o que pode se tornar um empecilho para análises quantitativas. Disso decorre que a extensão da noção de variável linguística, da fonologia para outros níveis gramaticais, não é isenta de problemas. A situação torna-se mais complexa ao lidarmos com variáveis discursivas, que requerem não só a extensão do modelo analítico variacionista para além do nível oracional, mas também uma revisão do requisito de equivalência semântica

Desde a década de 1970, alguns sociolinguistas têm questionado a utilização da metodologia variacionista na análise de fenômenos linguísticos além da 
fonologia (cf. LAVANDERA, 1978; ROMAINE, 1984; entre outros) - questão que é ainda retomada e discutida por quem se dedica ao estudo de fenômenos mais altos (cf. TAVARES, 2003; FREITAG, 2009; ROST SNICHELOTTO, 2009; VALLE, 2014; entre outros). A noção de "mesmo significado", atrelada originariamente ao plano representacional ou referencial, passa a ser interpretada, nesses casos, como "comparabilidade funcional" (LAVANDERA, 1978, p. 181), ou "mesma função comunicativa" (MILROY; GORDON, 2003, p. 170). Vale ressaltar aqui que restrições discursivas que atuam sobre o uso de certos itens podem impedi-los de se comportarem como variantes em certos contextos. Isso remete ao princípio da contabilidade (accountability) e à noção de envelope da variação, conceitos fundamentais na Sociolinguística Variacionista: além de se examinar uma dada forma variável, é preciso levantar todas as formas variantes potenciais que concorrem com aquela em um mesmo contexto, ou seja, é preciso determinar o envelope de variação (MILROY; GORDON, 2003; LABOV, 2008)².

Certos trabalhos referidos por Milroy e Gordon (2003), ao tratarem de equivalência semântica e contexto discursivo, sugerem que a direção da análise deve ser a seguinte: em vez de se partir de uma certa forma, é preciso partir dos contextos discursivos em que a forma é usada, identificando suas funções discursivas e, então, as formas que estão disponíveis para desempenhar tais funções. Nos termos de Tagliamonte (2006), diferentes formas podem ser usadas para a mesma função, particularmente no caso de mudança linguística em curso, evidenciando uma instabilidade na relação entre forma-função. À medida que as análises variacionistas vão atingindo níveis gramaticais mais altos, a correlação forma-significado referencial vai se deslocando para forma-função discursiva. Esse ponto será retomado adiante.

\subsection{ANÁLISE SOCIOLINGUísticA DE FENÔMENOS DISCURSIVOS}

Começamos esta seção nos reportando ao trabalho pioneiro de Silva e Macedo (1996) sobre análise sociolinguística de marcadores conversacionais no português do Brasil, que correlaciona, de modo geral, os fenômenos analisados

\footnotetext{
2 Vale notar que Labov $(1982 ; 2008)$ prevê, de acordo com o princípio da contabilidade, que devem ser computadas também as não ocorrências de dada variante em contextos relevantes; ressalva, porém, que nem sempre é possível delimitar o conjunto de possíveis variantes. No português, por exemplo, há variáveis binárias, como a expressão do sujeito, que são compostas por duas variantes objetivamente reconhecidas: sujeito expresso versus não expresso ou apagado; já no plano das variáveis discursivas, dificilmente se consegue identificar com alguma confiabilidade contextos de não ocorrência de dada variante.
} 
a fatores sociais, tomando esse estudo como exemplar para fomentar o início da discussão aqui proposta. As autoras apresentaram uma classificação geral dos marcadores, dentre os quais se destacam os "requisitos de apoio discursivo" RADs (né?, tá?, sabe?, entendeu? etc.) e os "iniciadores" (bom, bem, olha, ah etc.), entre outros. A análise quantitativa realizada tomou-os como tipos (por exemplo, RADs) e não como ocorrências específicas (né?, tá?, sabe?, entendeu? etc.). No caso dos RADs, o estudo mostra que não houve diferenças significativas em relação à estratificação social dos informantes, mas que tais itens ocorrem predominantemente em trechos argumentativos, em passagens mais longas nas entrevistas, com assuntos conhecidos e considerados subjetivos. No caso dos iniciadores, as mulheres apresentaram maior uso que os homens e os itens examinados apresentaram algumas especificidades funcionais.

Esse tipo de análise, especialmente a feita com os RADs, não trata o fenômeno como uma variável constituída por diferentes variantes, comparáveis entre si, mas como um bloco único, sendo a variação discursiva associada a usos tipificados que agregam várias formas que, em conjunto, são correlacionadas a fatores externos (e por vezes também a internos), obtendo-se frequências gerais de uso. Nesse ponto, há uma diferença bastante significativa em relação a estudos que focalizam variáveis fonético-fonológicas ou morfossintáticas, por exemplo, já que, nesses, cada variável (dependente) se desdobra em suas respectivas variantes, que são submetidas a uma análise multivariada. ${ }^{3}$

A realização de análises multivariadas com itens discursivos no português começou a se intensificar na década de 2000, tomando como variáveis: aí, daí, então e $e$ (TAVARES, 1999; 2003); sabe?, não tem? e entende? (VALLE, 2001; 2014); tá? e certo? (FREITAG, 2001); olha e veja (ROST SNICHELOTTO, 2002; 2009); bom e bem (MARTINS, 2003); acho (que) e parece (que) (FREITAG, 2003); entre outras pesquisas. Alguns desses itens se comportam tipicamente como marcadores discursivos de base interacional, outros têm características textuais e outros mostram comportamento híbrido. Trabalhos dessa natureza enfrentam, de início, a seguinte problemática: o que é preciso considerar para se

\footnotetext{
3 Análises multivariadas medem, simultaneamente, a influência de diversas variáveis independentes, externas e internas, atribuindo pesos relativos aos fatores condicionadores e selecionando aquelas que são estatisticamente relevantes para o uso da variante escolhida como "aplicação da regra". O pacote estatístico GoldVarbX (SANKOFF; TAGLIAMONTE; SMITH, 2005) é um modelo que costuma ser aplicado nesse tipo de análise. Mais recentemente, tem-se utilizado também modelos de efeitos mistos por meio do programa R (R CORE TEAM, 2013) no pacote Rbrul (JOHNSON, 2009). Tais modelos permitem análises de correlações entre dois tipos de variáveis independentes e uma variável dependente, testando efeitos fixos (como sexo do informante, classe morfológica da palavra) e efeitos aleatórios (de cada indivíduo, de cada item lexical), e verificando se as correlações observadas se devem a efeitos fixos ou a efeitos aleatórios.
} 
levar a cabo a tarefa de delimitar um objeto de estudo e transformá-lo em uma variável discursiva que pode ser operacionalizada em uma análise quantitativa multivariada?

Essa indagação é o fio condutor das subseções seguintes, que tratam de: passos iniciais da pesquisa variacionista com fenômenos discursivos; procedimentos para delimitação de variáveis discursivas; e critérios para delimitação de itens discursivos do subgrupo dos RADs.

\subsubsection{DELINEANDO O ENVELOPE DE VARIAÇÃO DE FENÔMENOS DISCURSIVOS: PASSOS INICIAIS}

Acreditamos que o ponto de partida para a delimitação de variáveis discursivas é a escolha do fenômeno discursivo a ser investigado e, consequentemente, da(s) linha(s) teórica(s) da pesquisa. Vamos ilustrar nossa exposição com um fenômeno já várias vezes referido neste capítulo: os marcadores discursivos - entendidos, na perspectiva de Schiffrin $(1987,2001)$, como itens multifuncionais que, atuando simultaneamente em vários domínios comunicativos (cognitivo, textual, social e expressivo), contribuem para a coesão e a coerência discursiva. Delimitando melhor o objeto, vamos nos ater aos RADs, definidos como itens essencialmente interacionais que atuam "no discurso oral como elementos focalizadores, dando relevo a certas partes do texto/discurso e contribuindo tanto para a interação falante-ouvinte, quanto para a organização discursiva" (VALLE, 2014, p. 230).

Um fenômeno discursivo (na perspectiva do que estamos entendendo como discursivo) deve ser ancorado teoricamente em uma perspectiva funcionalista da língua, que inclui níveis mais altos no âmbito gramatical. A concepção de gramática a ser adotada é a de gramática baseada no uso, vista como um organismo maleável que se adapta às necessidades cognitivas e comunicativas dos falantes (BYBEE, 2006; GIVÓN, 2002), englobando não só fonologia, morfossintaxe e semântica, mas também aspectos pragmáticos inferenciais (TRAUGOTT, 1995). De acordo com essa abordagem, a gramática envolve um repertório de itens que, usados inicialmente de maneira expressiva, se tornam rotinizados por sua recorrência em certos contextos, estabelecendo padrões linguísticos. O aumento da frequência de uso de determinado item em diferentes contextos pode ser indício de difusão linguística e social de mudança (BYBEE, 2010) - processo lento e gradual em que os itens em jogo vão perdendo algumas propriedades e ganhando outras.

Considerando-se a interação entre aspectos cognitivos e comunicativos/ contextuais, a emergência e a difusão de padrões de uso costumam ser explicadas como um processo de gramaticalização - entendida aqui como "[...] mudança pela qual itens lexicais e construções passam, em certos contextos linguísticos, a desempenhar funções gramaticais e, uma vez gramaticalizados, continuam 
a desenvolver novas funções gramaticais" (HOPPER; TRAUGOTT, 2003, p. 18). E ainda: "[...] processo pelo qual um item lexical [ou uma construção], impulsionado por certo contexto pragmático e morfossintático, torna-se gramatical” (TRAUGOTT, 1995, p. 1). Há dois tipos de mudança envolvidos em processos de gramaticalização: mudança semântico-pragmática e mudança categorial. $\mathrm{Na}$ análise de marcadores discursivos na perspectiva funcionalista de gramaticalização, leva-se em conta: a) o papel do significado do item fonte e sua expansão a outros contextos de uso, linguístico e situacional, para o estabelecimento de suas funções nos vários domínios discursivos; e b) a migração dos itens de uma categoria a outra.

Um ponto a ser destacado aqui é que a Teoria da Variação e Mudança não é uma teoria da gramática. Entre os postulados básicos da TVM, destacam-se: (i) a língua é um sistema inerentemente heterogêneo e ordenado; (ii) as formas da língua veiculam, além de significados representacionais, também significados sociais e expressivos;(iii) o locus do estudo da língua é a comunidade de fala e não o indivíduo; (iv) fatores linguísticos e extralinguísticos encontram-se intimamente relacionados no desenvolvimento da mudança linguística, que não é uniforme nem instantânea; (v) na língua, nem tudo que varia sofre mudança, mas toda mudança pressupõe variação; (vi) o entendimento de processos que operaram sobre a língua no passado pode ser inferido da observação de processos em curso no presente (WEINREICH; LABOV; HERZOG, 2006; COELHO et al., 2015).

A depender do fenômeno linguístico a ser analisado, cabe ao pesquisador articular os pressupostos da TVM com uma teoria linguística, seja de natureza formal ou funcional. Assim, no caso do fenômeno discursivo tomado aqui como exemplar, há necessidade de se estabelecer um alinhamento teórico entre a TVM e a abordagem funcionalista da gramaticalização. Não vamos nos aprofundar nessa interface. Uma discussão detalhada dessa articulação teórica pode ser conferida nos textos de Görski e Tavares (2013), Tavares (2003; 2013), Valle (2014), Tavares e Görski (2015), entre outros.

Uma vez escolhido o fenômeno discursivo a ser investigado e a abordagem teórica da pesquisa, há outros aspectos que precisam ser considerados: a necessidade de uma amostra representativa de uma comunidade de fala e a necessidade de um conjunto de critérios a serem aplicados para identificar as variantes em jogo. Nesse caso, entra em cena o princípio da contabilidade e a definição do envelope de variação, aspectos considerados a seguir. 


\subsubsection{PROCEDIMENTOS PARA DELIMITAÇÃO DE VARIÁVEIS DISCURSIVAS}

Conforme já apontado, a expansão da noção de variável linguística para níveis mais altos não é uma questão trivial. Labov (1978) propõe que o que garante que um fenômeno seja considerado variável é o isolamento e a definição dos elementos que variam ao longo das mesmas dimensões em resposta ao mesmo estado de coisas, e o isolamento do contexto em que a variação se encontra, gradualmente separando aqueles casos em que o mesmo item tem diferentes funções linguísticas, deixando de lado contextos em que a variação é neutralizada ou onde a regra é categórica. Como já vimos, esses dois requisitos precisam ser revistos quando tratamos de variação discursiva - o que já vem sendo feito no âmbito da Sociolinguística -, não só realinhando o critério de comparabilidade semântica para comparabilidade ou equivalência funcional no discurso (cf. LAVANDERA, 1978; ROMAINE, 1984; NARO; BRAGA, 2000; GÖRSKI et al., 2003; TERKOURAFI, 2011; entre outros.), como também buscando arranjar mecanismos metodológicos adequados para lidar com a multifuncionalidade característica dos itens discursivos. A respeito desse último aspecto, Pichler (2010) avalia que, apesar das evidências de que unidades discursivas estão envolvidas nos padrões de variação e mudança linguística, itens como oh, well, I mean, you know, entre outros, não têm sido tradicionalmente explorados nos estudos sociolinguísticos pela falta de um conjunto coerente de princípios metodológicos para a análise de unidades discursivas devido, entre outros fatores, à multifuncionalidade das unidades discursivas e à falta de métodos claros para o controle e a descrição da multifuncionalidade. Essa avaliação, no entanto, já não se aplica ao português, pois, conforme dito anteriormente, análises variacionistas de marcadores discursivos vêm sendo desenvolvidas há mais de uma década, com ajustes metodológicos cada vez mais refinados.

Em face da controvérsia que envolve a questão de equivalência semântica/ funcional, mais especificamente quando se verifica expansão de significado de uma forma para outro(s) contexto(s) de uso, Sankoff e Thibault (1981) introduzem a noção de "fraca complementaridade", envolvendo aumento/decréscimo complementar de frequência absoluta de duas construções ao longo do tempo ou de outra dimensão extralinguística, em razão de suas propriedades distribucionais em uma comunidade de fala. Conforme pontua Tagliamonte (2006), o critério relevante deixa de ser a equivalência semântica e passa a ser a equivalência discursiva ou funcional. Em muitos casos, o que se pode dizer é que "as variantes propostas podem servir a uma função ou, mais geralmente, a funções discursivas similares" (SANKOFF; THIBAULT, 1981, p. 208). Os autores, no entanto, problematizam a demarcação de funções discursivas, o que tem levado a importantes discussões 
na área (cf. SCHWENTER; CACOULLOS, 2010; TAGLIAMONTE, 2006; 2012; entre outros). Na prática, a noção de domínio funcional - entendido como uma área da gramática que envolve diferentes camadas (HOPPER, 1991) que codificam funções idênticas ou similares a outras, mais antigas no desempenho das funções em questão - tem se mostrado fundamental na análise da variação discursiva, o que nos leva à revisão do segundo requisito laboviano para o tratamento de um fenômeno variável.

$\mathrm{O}$ isolamento do contexto de variação traz à tona a questão da multifuncionalidade dos itens discursivos. Qual função devemos levar em conta para identificar a variável discursiva quando lidamos com itens multifuncionais? Görski et al. (2003) salientam que cada variável discursiva pode ser correlacionada a domínios funcionais específicos, configurando-se como um fenômeno superordenado e gradiente que envolve macrofunção $>$ funções $>$ subfunções, e que o recorte da variável pode se dar em cada um dos níveis dessa hierarquia funcional. Várias pesquisas já foram desenvolvidas tomando fenômenos discursivos como variáveis a partir do recorte em suas macrofunções, tais como a de sequenciação retroativa-propulsora de informações em que $e$, aí, dai e então são variantes (TAVARES, 2003) e a de chamada de atenção do ouvinte, recobrindo as variantes olha e $v \hat{e}$ (ROST SNICHELOTTO, 2009), entre outros. Nas situações em que os itens de um domínio funcional tomado como variável discursiva desempenham subfunções, estas são controladas como variáveis independentes (ou correlacionadas), de modo a captar particularidades contextuais relevantes (cf. nota 3).

Pichler (2010) salienta que, quando nos propomos a uma análise sociolinguística de dois ou mais itens discursivos, é necessário, inicialmente, identificar com clareza, por meio de um estudo qualitativo prévio, as funções discursivas e os itens que estão em competição em um mesmo (macro/micro) domínio funcional, de modo a subsidiar seu tratamento como itens em variação e o levantamento dos condicionadores linguísticos e extralinguísticos que podem atuar sobre os itens em análise. Interessada na delimitação de unidades discursivas no contexto da TVM, a autora menciona que tanto parâmetros funcionais quanto formais podem ser utilizados para delimitar variáveis dessa natureza e que muitos outros aspectos podem entrar em jogo: "o que é importante é que os pesquisadores sejam consistentes em como eles conceptualizam partículas discursivas específicas e que estabeleçam claramente como delimitam o contexto variável" (PICHLER, 2010, p. 591). De modo complementar, Schwenter e Cacoullos (2010), tratando de fenômenos variáveis no âmbito do tempo-aspecto em espanhol, propõem, para a delimitação de variáveis de nível mais alto, uma abordagem baseada na forma e na função, sob a ótica da fraca complementaridade (forma) e da expansão de contextos de uso via gramaticalização (função). Essa orientação metodológica é fundamental no tratamento de variáveis discursivas. 


\subsubsection{CRITÉRIOS PARA DELIMITAÇÃO DE RADS}

Valle (2014) estabeleceu critérios para a delimitação de RADs, que, em conjunto, possibilitam um recorte mais preciso dos itens tomados como objeto de estudo. Dentre os critérios elencados pela autora, vamos nos ater a comentar três que podem ter uma aplicação mais geral para itens de natureza discursiva: 1) critério de unidade funcional e de compartilhamento de contextos de uso; 2) critério de unidade conceptual e classe gramatical de origem; 3) critério de frequência de uso dos itens. Os critérios propostos não são entendidos como baliza de exclusão ou inclusão de itens, mas como guia para orientar a seleção do grupo de itens mais coeso possível para a análise. Nem todos os critérios têm o mesmo peso ou independência; por exemplo, o primeiro critério se sobrepõe aos demais, uma vez que a unidade funcional e o compartilhamento de contextos de uso é o principal fio condutor de análises variacionistas de unidades discursivas, mas, ainda assim, pode ser fortemente afetado pelo último, já que para a realização de análises quantitativas a frequência dos dados é relevante. Tomamos esses critérios para ilustrar as etapas de checagem das formas candidatas a variantes da variável discursiva que atua no domínio funcional da "requisição de apoio discursivo".

\subsubsection{CRITÉRIO DE UNIDADE FUNCIONAL E DE COMPARTILHAMENTO DE CONTEXTOS DE USO}

Caracterizado como um subgrupo dos marcadores discursivos, o conjunto de itens que reúne partículas com função basicamente interacional tem recebido nomenclatura variada: "requisitos de apoio discursivo" - RADs ${ }^{4}$ (SILVA; MACEDO,1996); "busca de aprovação discursiva” - BADs (MARCUSCHI, 1989; URBANO, 1997); "marcadores de controle de contato" - MCCs (BRIZ, 2001 apud NÚÑEZ, 2011; PORTOLÉS, 2007). Sob esses rótulos têm sido inseridos itens que compartilham funções interacionais mas que são de natureza ainda heterogênea, tais como né?, sabe?, entendeu?, tá?, certo?, viu?, heim?, entre outros.

Briz (2001 apud NÚÑEZ, 2011), referência importante para vários trabalhos em espanhol, considera que os marcadores de controle de contato podem ser usados para: a) reforçar ou justificar o raciocínio dos falantes para seu(s) interlocutor(es); b) manter ou verificar o contato entre os participantes da conversação; c) envolver

\footnotetext{
${ }^{4}$ Nomenclatura mais difundida no Brasil.
} 
ativamente o interlocutor - funções de caráter basicamente interacional, focadas na relação entre o falante e sua audiência. Embora a direção dos estudos atuais leve em conta não apenas o plano interacional, mas os vários planos de atuação dos marcadores discursivos considerando a ampla gama funcional desses elementos (cf. ROST SNICHELOTTO, 2009; VALLE, 2001; 2014), tomar a propriedade basicamente interacional acima descrita é um primeiro passo importante para delimitar os RADs, tornando o conjunto em análise mais unificado. Outro passo importante é levar em consideração o compartilhamento de contextos de uso.

À primeira vista, né?, tá?, viu? e certo?, juntamente com sabe? e entendeu?, parecem cumprir tal requisito. Vejamos as ocorrências abaixo, extraídas da amostra Brescancini-Valle (VALLE, 2014, p. 51-64; 197) ${ }^{5}$ :

(1) F: Assim:: pra se divertir? Ah, eu saio à noite assim, mas não na noite assim toda a hora, né? Eu vou na casa das minhas amigas, eu vou comer pizza, eu vou fazer um lan::che, eu::eu vou dormir na casa de::las, sabe? Coisa assim bem:: normalzinha assim, que tipo sair assim eu sou muito nova ainda, né? aí não dá, né? (BARRA02FJ8)

(2) F:O meu marido é uma pessoa boa...tá? muito bom, ele me acompanhou, ele me deu a maior for::ça... (BARRA20FA8)

(3) F: E a mulher é isso... mulher caiu uma vez caiu duas... não se levantou:: não adianta que aquilo custa a se levantar mais... mas se ela se (hes) se ela acha que quer se levantar uma vez ou duas ela se levanta que nunca mais cai (est)... nunca mais cai, nunca mais, nunca mais... mas se ela não souber ela vai caindo e cada vez caindo mais (hes) aí depois pra se levantar só pela natureza (est), mas por ela não se levanta mais... (est) certo?Então aí:: passou a mão então ficou assim. (BARRA45MB4)

(4) F: Foi um lugar também muito bom de pesca, viu? as pescaria aqui era conduzido pela Lagoa (BARRA45MB4)

(5) F: Ah:: as avós era mais (hes) como eu digo, cuidar dos filhos, entendeu? Cuidar dos filhos, mais (hes) o serviço da casa e também elas auxiliavam assim ó, quando-nas plantações porque os avôs quando vinham eles deixavam- alguns tinham terras em maior número. (BARRA13MJ11)

Em relação a né?, comumente considerado como pontuante discursivo com o papel fundamental de elemento rítmico, estudos têm mostrado que seu comportamento se diferencia dos demais RADs, notadamente pela alta frequência de uso (sendo facilmente usado mais de 300 vezes em apenas uma entrevista)

\footnotetext{
5 Valle (2014) analisou 45 entrevistas sociolinguísticas que compõem a Amostra Brescancini-Valle..
} 
e pelo seu leque amplo de posições intra e entre constituintes (cf. URBANO, 1999; VALLE, 1999; MARTELOTTA, 2004). Itens como sabe? e entendeu?, em contrapartida, ocorrem principalmente entre orações ou em final de enunciados/ turnos, pospostos ao constituinte ou enunciado que frisam e pouco cercados de pausas e estímulos. Tal diferença contextual justifica o descarte de né? em prol de um grupo mais coeso.

\subsubsection{CRITÉRIO DE UNIDADE CONCEPTUAL E CLASSE GRAMATICAL DE ORIGEM}

Esse critério diz respeito ao processo de gramaticalização, que culminou no uso discursivo dos itens em análise. Os verbos ver, perceber, saber, entender e compreender são de natureza cognitiva, expressando processos que, a princípio, diferem entre si em grau de complexidade: em seu significado de origem, ver e perceber, voltados a atividades perceptuais mais concretas, seriam menos complexos que verbos como entender e compreender, que envolvem processos mentais. No entanto, o uso que os falantes fazem desses verbos indica que em muitos casos não existem delimitações claras entre esses itens. Sweetser (1990), por exemplo, observa que falantes de inglês usam see (ver) no sentido de know (saber/conhecer) ou understand (entender/compreender). Em português, Ferreira (1976) aponta que o verbo saber, que deriva do latim sapere, se ramifica em dois grupos de sentidos distintos, um ligado a experiências físicas (ter sabor, ter cheiro, ter gosto) e outro ligado a propriedades mentais (discernimento, conhecimento, compreensão).

Essa proximidade de sentidos originais se reflete na manutenção de certos traços nas formas em gramaticalização, conforme prevê o princípio da persistência de Hopper (1991). Isso justificaria o desenvolvimento de alguns verbos de cognição e de percepção em MDs que compartilham funções e contextos em um mesmo domínio funcional, não só em português (percebe?, viu/visse?, sabe(s)?, entende(s)/ entendeu?, compreende?, entre outros) como em outras línguas: y'know (em inglês); ¿̇(me) entiendes?, ¿sabes?, ¿̇cachái? (em espanhol); tu sais?/vous savez?, tu comprends?/vous comprenez? (em francês); sai?, sai com'è,capisci?, puoi capire?, capito? (em italiano) (VALLE, 2014). Esse comportamento interlinguístico se explica a partir da premissa funcionalista de que em diferentes línguas são encontradas formas que se agrupam como membros de metatipos mais gerais, entendidos como domínios funcionais (GIVÓN, 2002).

Com base no cenário acima descrito, podemos considerar que itens derivados de sentidos-fonte semelhantes e da mesma classe gramatical de origem desenvolvam sentidos-alvo semelhantes, apresentando maior proximidade 
funcional em sua trajetória, do que itens originariamente muito diferentes entre si. Desse modo, tá?, certo?, ok?, beleza?, tranquilo?, apesar de compartilharem atualmente algumas funções e contextos com os RADs derivados de verbos de cognição, são descartados na busca de itens intercambiáveis e com percursos de mudança semelhantes.

Note-se que tá? e certo?, por exemplo, embora barrados pelo critério em pauta, podem ser tratados como variantes se o parâmetro de seleção das formas intercambiáveis for apenas o critério de unidade funcional e de compartilhamento de contextos de uso. Freitag (2001) analisou tá? e certo? como variantes, verificando a distribuição de frequência de cada um desses elementos correlacionada às variáveis sociais sexo, idade e escolaridade, e ainda aos tipos de sequência discursiva em entrevistas de Florianópolis (Projeto Variação Linguística na Região Sul do Brasil - VARSUL).

\subsubsection{CRITÉRIO DE FREQUÊNCIA DE USO DOS ITENS}

A princípio, se considerou a possibilidade de incluir na análise vários itens originados de verbos de cognição ou de percepção, como viu?, visse?, percebe(s)?, compreende(s)?, conforme ilustrado a seguir (VALLE, 2014, p. 64):

(9) F: Ó que bonitinho!

E: Ó que amor!

F: Tu não tem filho?

E: Não.

F: Da Ortopé ainda que chique, visse? (BARRA23FA10)

(10) F: Foi um lugar também muito bom de pesca, viu? as pescaria aqui era conduzido pela Lagoa (BARRA45MB4)

(11) F: Agora, o que é de agora eu não sei, compreendes comé? (est) (est)...e às vezes aqui eu vou nessas conta mesmo, eu não sei, sei do anti- o que era do antigo, agora fazer como (hes) como eles faziam antigamente, eu faço. (BARRA33FB0)

A autora constatou, contudo, que percebe(s)? não é usado na amostra analisada e que o uso de viu?, visse? e compreende(s)? é raro, não chegando ao total de 10 dados para as três formas juntas. Sendo assim, pelo critério de frequência de uso dos itens, os elementos mencionados foram descartados.

\subsubsection{SELECIONANDO OS ITENS PARA COMPOR O OBJETO DE ESTUDO A PARTIR DA APLICAÇÃO DOS CRITÉRIOS}

Após a aplicação dos critérios, resta o total de sete formas que atendem 
a pelo menos dois dos três critérios estabelecidos (cf. Quadro 4.1). A amostra de Valle (2014) contém 1.610 ocorrências de marcadores que foram analisadas como variantes da variável discursiva RADs.

\begin{tabular}{|l|c|c|c|}
\hline $\begin{array}{l}\text { Formas incluídas } \\
\text { na análise }\end{array}$ & $\begin{array}{l}\text { Critério 1 } \\
\text { (função e contexto) }\end{array}$ & $\begin{array}{l}\text { Critério 2 } \\
\text { (significado e classe de origem) }\end{array}$ & $\begin{array}{l}\text { Critério 3 } \\
\text { (frequência de uso) No de ocorrências }\end{array}$ \\
\hline Sabe? & $\checkmark$ & $\checkmark$ & $\checkmark(660)$ \\
\hline Sabes? & $\checkmark$ & $\checkmark$ & $-(7)$ \\
\hline Entende? & $\checkmark$ & $\checkmark$ & $-(15)$ \\
\hline Entendeu? & $\checkmark$ & $\checkmark$ & $\checkmark(522)$ \\
\hline Entendesse? & $\checkmark$ & $\checkmark$ & $\checkmark(303)$ \\
\hline Tá entendendo? & $\checkmark$ & $\checkmark$ & $\checkmark(66)$ \\
\hline Tás entendendo? & $\checkmark$ & $\checkmark$ & $-(37)$ \\
\hline
\end{tabular}

Quadro 4.1 - Adequação das formas em análise à proposta de critérios unificadores para a delimitação de variáveis discursivas (Fonte: adaptado de Valle, 2014, p. 65).

Ressaltamos que o estabelecimento de critérios serve para orientar o pesquisador na delimitação do envelope de variação de fenômenos discursivos, mas devem ser pensados a partir do objeto em estudo e dos objetivos de cada pesquisa. Nesse sentido, se os critérios fossem aplicados à risca, sabes?, entende? e até mesmo tás entendendo? deveriam ser excluídos da análise por conta da baixa frequência. No entanto, no trabalho aqui reportado, a autora optou por manter esses itens já que seu interesse também estava relacionado ao processo de gramaticalização desses marcadores, sendo importante manter todas as formas derivadas dos dois verbos e que são usadas como MDs na amostra investigada.

Além de contribuir para o estabelecimento do envelope de variação, o levantamento das formas variantes a partir de critérios unificadores previamente estipulados também pode auxiliar o pesquisador no momento da análise quantitativa. O trabalho de Valle (2014), por exemplo, envolveu duas variáveis dependentes distintas: em um primeiro momento, as formas derivadas de saber, amalgamadas em uma macroforma, foram contrapostas às formas derivadas de entender, também amalgamadas, realizando-se uma análise multivariada, em busca de resultados relacionados com os contextos de uso linguístico de cada tipo de RAD e com seu percurso de gramaticalização. Em um segundo momento, ao lidar com questões relacionadas a aspetos sociais, identitários e estilísticos, foram agrupadas as formas que potencialmente carregam alguma marca identitária 
(entendesse?, sabes? e tás entendendo $\left.{ }^{6}\right)$ em contraste com aquelas que seriam neutras (sabe?, entende?, entendeu? e tá entendendo?), realizando-se também uma análise multivariada. Para cada uma dessas variáveis operacionalizadas a partir dos RADs, foram testados grupos de fatores organizados em função de objetivos e hipóteses específicas do trabalho.

\subsection{CONSIDERAC̣ÕES FINAIS}

Buscamos, neste capítulo, discutir aspectos do tratamento sociolinguístico dispensado a variáveis discursivas, com ênfase na organização do envelope de variação, apresentando critérios, cuja aplicação foi ilustrada na delimitação de requisitos de apoio discursivo. Após uma contextualização acerca do estado da arte concernente ao assunto, foram destacados os seguintes passos: a) escolha do fenômeno discursivo a ser investigado (no caso em tela, RADs, um subtipo de marcadores discursivos); b) abordagem teórica da pesquisa (neste caso, uma articulação entre a TVM e o funcionalismo com foco na gramaticalização); c) desenho do envelope de variação (a variável discursiva foi caracterizada como um domínio funcional representado por diversas camadas/variantes); d) estabelecimento de critérios unificadores aplicados para isolar as variantes em jogo (de unidade funcional e compartilhamento de contextos de uso; de unidade conceptual e classe gramatical de origem e de frequência de uso dos itens). Acreditamos que os passos apresentados podem funcionar como um roteiro metodológico para orientar o pesquisador no tratamento de variáveis discursivas.

\subsection{REFERÊNCIAS}

BYBEE, J. From usage to grammar: the mind's response to repetition. Language, v. 82, n. 4, p. 711-733, 2006. Press, 2010.

. Language, usage and cognition. Cambridge: Cambridge University

COELHO, I. L. et al. Para conhecer sociolinguística. São Paulo: Contexto, 2015.

6 Considerou-se que as formas sabes? e tás entendendo? podem ser tomadas como marcas de identidade local (como é o caso de entendesse?), por carregarem marca morfológica de concordância com o pronome tu, uma das características do falar ilhéu (cf. LOREGIAN-PENKAL, 2004; DAVET, 2013). 
DAVET, J. C. T. Estudo da concordância verbal de segunda pessoa do singular em Florianópolis-SC: algumas implicações identitárias. Dissertação (Mestrado em Linguística) - Programa de Pós-graduação em Linguística, Universidade Federal de Santa Catarina, Florianópolis, 2013.

FERREIRA, A. Dicionário de Latim-Português. Porto: Porto Editora Ltda., 1976.

FREITAG, R. M. K. O uso de tá? e certo? na fala de Santa Catarina. Working Papers em Linguística, Florianópolis, n. 5, p. 25-41, 2001.

FREITAG, R. M. K. Gramaticalização e variação de acho (que) e parece (que) na fala de Florianópolis. Dissertação (Mestrado em Linguística) - Programa de Pós-Graduação em Linguística, Universidade Federal de Santa Catarina, Florianópolis, 2003.

- Problemas teórico-metodológicos para o estudo da variação linguística nos níveis gramaticais mais altos. Matraga, Rio de Janeiro, v. 16, n. 24, p. 115-132, 2009.

GIVÓN, T. Bio-linguistics: the Santa Barbara lectures. Amsterdam: John Benjamins, 2002.

GÖRSKI, E. M.; COELHO, I. L.; NUNES DE SOUZA, C. M (Org.). Variação estilística: reflexões teórico-metodológicas e propostas de análise. Florianópolis: Insular, 2014.

GÖRSKI, E. M. et al. Fenômenos discursivos: resultados de análises variacionistas como indícios de gramaticalização. In: RONCARATI, C.; ABRAÇADO, J. (Org.). Português brasileiro: contato linguístico, heterogeneidade e história. Rio de Janeiro: 7Letras: FAPERJ, 2003, p. 106-122.

GÖRSKI, E. M.; TAVARES, M.A.; FREITAG, R. M. K. Restrições de natureza cognitivo-comunicativa: marcação versus expressividade retórica em fenômenos variáveis. In: RONCARATI, C.; ABRAÇADO, J. (Org.). Português Brasileiro II: contato linguístico, heterogeneidade e história. Rio de Janeiro: 7Letras, 2008, p. 101-117.

GÖRSKI, E. M.; VALLE, C. R. M. Marcadores em competição no domínio funcional da "requisição de apoio discursivo". In: CEZARIO, M. M.; FURTADO DA CUNHA, M. A. (Org.). Linguística centrada no uso: uma homenagem a Mário Martelotta. Rio de Janeiro: Mauad X: FAPERJ, 2013. p. 113-129.

GÖRSKI, E. M.; TAVARES, M. A. Reflexões teórico-metodológicas a respeito de uma interface sociofuncionalista. Revista do Gelne, Caicó, v. 15, n. 1/2, p. 75 97, 2013.

HOPPER, P. On some principlesof grammaticization. In: TRAUGOTT, E.; HEINE, B. (Ed.). Approaches to Grammaticalization. Amsterdam: John Benjamins, 1991. p. 17-35. 
HOPPER, P.; TRAUGOTT, E. Grammaticalization. 2. ed. Cambridge: Cambridge University Press, 2003.

LABOV, W. Where does the linguistic variable stop? A response to Beatriz Lavandera. Working Papers in Sociolinguistics, Philadelphia, v. 44, p. 1-22, 1978. . Building on empirical foundations. In: LEHMANN, W. P.; MALKIEL, Y. (Eds.). Perspectives on Historical Linguistics. Amsterdam: John Benjamins, 1982, p. 17-92.

- Padrões sociolinguísticos. Tradução de Marcos Bagno, Marta Scherre e Caroline Cardoso. São Paulo: Parábola, 2008.

. Quantitative reasoning in linguistics. 2008. Disponível em: <http:// www.ling.upenn.edu/ wlabov/home.html>. Acesso em: 15 abr. 2015.

LAVANDERA, B. Where does the sociolinguistic variable stop?. Cambridge: Language in Society, n. 7, p. 171-82, 1978.

LOREGIAN-PENKAL, L. (Re)análise da referência de segunda pessoa na fala da Região Sul. Tese (Doutorado em Letras) - Programa de Pós-Graduação em Letras, Universidade Federal do Paraná, Curitiba, 2004.

MACAULAY, R. Discourse variation. In: CHAMBERS, J.; TRUDGILL, P.; SCHILLING-ESTES, N. (Ed.). The handbook of language variation and change. Oxford: Blackwell, 2002, p. 1-18.

MACEDO, A. T. de; RONCARATI, C.; MOLLICA, M. C. (Org.). Variação $e$ Discurso. Rio de Janeiro: Tempo Brasileiro, 1996.

MARCUSCHI, L. A. Marcadores conversacionais do Português Brasileiro: formas, posições e funções. In: CASTILHO, A. (Org.). Português culto falado no Brasil. Campinas: Editora da UNICAMP, 1989. p. 281-321.

MARTELOTTA, M. E. Operadores argumentativos e marcadores discursivos. In: VOTRE, S. J.; CEZARIO, M. M.; MARTELOTTA, M. E. (Org.). Gramaticalização. Rio de Janeiro: Faculdade de Letras UFRJ, 2004. p. 82-136.

MARTINS, L. T. Bom e bem e suas multifunções na fala da Região Sul do Brasil. Dissertação (Mestrado em Linguística) - Programa de Pós-Graduação em Linguística, Universidade Federal de Santa Catarina, Florianópolis, 2003.

MILROY, L.; GORDON, M. Beyond phonology: analyzing and interpreting higher level variation. In: Sociolinguistics: method and interpretation. Oxford: Blackwell Publ, 2003. p. 169-197.

NARO, A. J.; BRAGA, M. L. A interface sociolinguística/gramaticalização. Gragoatá, Niterói, n. 9, p. 125-134, 2000.

NÚÑEZ, A. S. M. Los marcadores interrogativos de control de contacto em el corpus PRESEEA de Santiago de Chile. Boletin de Filología, Santiago, v. XLVI, n. 2, p. 135-166, 2011.

PAIVA, M. da C.; SCHERRE, M. M. P. Retrospectiva sociolinguística: contribuições do PEUL. Revista DELTA, São Paulo, v. 15, n. especial, p. 201-232, 1999. 
PICHLER, H. Methods in discourse variation analysis: reflections on the way forward. Journal of Sociolinguistics, Hoboken, v. 14, n. 5, p. 581-608, 2010.

PORTOLÉS, J. Marcadores del discurso. 4. ed. Barcelona: Ariel, 2007.

R CORE TEAM. $\boldsymbol{R}$ : A language and environment for statistical computing. R Foundation for Statistical Computing, Vienna, Austria. 2013. Disponível em: $<$ http://www.R-project.org/>. Acesso em: 10 fev. 2016.

ROMAINE, S. On the problem of syntactic variation and pragmatic meaning in sociolinguistic theory. Folia Linguistica, Vigo, v. 18, n. 3-4, p. 409-437, 1984.

ROST, C. A. Olha e veja: multifuncionalidade e variação. Dissertação (Mestrado em Linguística) - Programa de Pós-Graduação em Linguística, UFSC, Florianópolis, 2002.

ROST SNICHELOTTO, C. A. Olha e vê: caminhos que se entrecruzam. Tese (Doutorado em Linguística) - Programa de Pós-graduação em Linguística, Universidade Federal de Santa Catarina, Florianópolis, 2009.

SANKOFF, D.; THIBAULT, P. Weak complementarity: tense and aspect in Montreal French. In: JOHNS, B.; STRONG D. R. (Ed.). Syntactic Change. Ann Arbor: University of Michigan Press, 1981, p. 205-216.

SANKOFF, D.; TAGLIAMONTE, S. A.; SMITH, E. Goldvarb X: a variable rule application for Macintosh and Windows. Toronto: Department of Linguistics; Ottawa: Department of Mathematics, 2005. Disponível em: <http://individual. utoronto.ca/tagliamonte/goldvarb.html>. Acesso em: 12 abr. 2016.

SCHIFFRIN, D. Discourse markers. Cambridge: Cambridge University Press, 1987.

. Discourse markers: language, meaning and context. In: SCHIFFRIN, D.; TANNEN, D.; HAMILTON, H. E. (Ed.). The handbook of discourse analysis. Malden: Blackwell, 2001. p. 54-75.

SCHWENTER, S. A.; CACOULLOS, R. T. Grammaticalization paths as variable contexts in weak complementarity in Spanish. In: WALKER, J. (Ed.). Aspect in grammatical variation. Amsterdam: John Benjamins, 2010. p. 13-26.

SILVA, G. M. de O.; SCHERRE, M. M. P. (Org.). Padrões sociolinguísticos. Rio de Janeiro: Tempos Linguísticos, 1996.

SILVA, G. M. de O.; MACEDO, A. T. de. Análise sociolinguística de alguns marcadores conversacionais. In: MACEDO, A. T. de; RONCARATI, C.; MOLLICA, M. C. (Org.). Variação e Discurso. Rio de Janeiro: Tempo Brasileiro, 1996. p. 11-49.

SWEETSER, E. From etymology to pragmatics: metaphorical and cultural aspects of semantic structure. Cambridge: Cambridge University Press, 1990.

TAGLIAMONTE, S. A. Analysing sociolinguistic variation. Cambridge: Cambridge University Press, 2006. 
Variationist Sociolinguistics: change, observation, interpretation. Cambridge: Wiley-Blackwell, 2012.

TAVARES, M. A. Um estudo variacionista de aí, daí, então e e como conectores sequenciadores retroativo-propulsores na fala de Florianópolis. Dissertação (Mestrado em Linguística) - Programa de Pós-Graduação em Linguística, Universidade Federal de Santa Catarina, Florianópolis, 1999.

A gramaticalização de e, aí, daí e então: estratificação/variação e mudança no domínio funcional da sequenciação retroativo-propulsora de informações - um estudo sociofuncionalista. Tese (Doutorado em Linguística) - Programa de Pós-graduação em Linguística, Universidade Federal de Santa Catarina, Florianópolis. 2003.

. Sociofuncionalismo: um duplo olhar sobre a variação e a mudança linguística. Interdisciplinar: Revista de Estudos em Lingua e Literatura, Itabaiana, v. 8, n. 17, p. 27-47, 2013.

TAVARES, M. A.; GÖRSKI, E. M. Variação e sociofuncionalismo. In: MARTINS, M. A.; ABRAÇADO, J. (Org.). Mapeamento Sociolinguístico do Português Brasileiro. São Paulo: Contexto, 2015, p. 249-270.

TERKOURAFI, M. The pragmatic variable: toward a procedural interpretation. Language in Society, Cambridge, n. 40, p. 343-372, 2011.

TRAUGOTT, E. C. The role of the development of discourse markers in a theory of grammaticalization. In: INTERNATIONAL CONFERENCE ON HISTORICAL LINGUISTICS, 12., 1995, Manchester. Proceedings...Manchester: [s.n.], 1995. Disponível em: <http://www.stanford.edu/ traugott/papers/discourse. pdf $>$. Acesso em: 20 fev. 2004.

URBANO, H. Marcadores conversacionais. In: PRETI, D. (Org.). Análise de textos orais. 3. ed. São Paulo: Humanitas, 1997. p. 81-101.

. Aspectos basicamente interacionais dos marcadores discursivos. In: NEVES, M. H. DE M. (Org.). Gramática do português falado. Campinas: Editora da UNICAMP, v. VII. 1999, p. 195-258.

VALLE, C. R. M. Os marcadores discursivos 'né?' e 'não tem?' na fala dos florianopolitanos. Relatório final de pesquisa do Programa Interinstitucional de Bolsas de Iniciação Científicas PIBIC/CNPq/UFSC biênio 1998-1999. UFSC, Florianópolis, 1999.

- Sabe? não tem? entende?: itens de origem verbal em variação como requisitos de apoio discursivo. Dissertação (Mestrado em Linguística) Programa de Pós-graduação em Linguística, Universidade Federal de Santa Catarina, Florianópolis, 2001.

.Multifuncionalidade, mudança e variação de marcadores discursivos derivados de verbos cognitivos: forças semântico-pragmáticas, estilísticas e identitárias em competição. Tese (Doutorado em Linguística) - Programa de Pós- 
graduação em Linguística, Universidade Federal de Santa Catarina, Florianópolis, 2014.

WEINER, J.; LABOV, W. Constraints on the agentless passive. Journal of Linguistics, Cambridge, v. 19, p. 29-58, 1983.

WEINREICH, U.; LABOV, W.; HERZOG, M. Fundamentos empíricos para uma teoria da mudança linguística. Tradução de Marcos Bagno. São Paulo: Parábola, 2006. 
